\title{
Höbelt, Lothar, Franz Joseph I. Der Kaiser und sein Reich. Eine politische Geschichte
}

\section{Paul Pasteur}

\section{OpenEdition}

\section{Journals}

Édition électronique

URL : http://journals.openedition.org/ifha/2241

DOI : 10.4000/ifha.2241

ISSN : 2198-8943

\section{Éditeur}

IFRA - Institut franco-allemand (sciences historiques et sociales)

Référence électronique

Paul Pasteur, « Höbelt, Lothar, Franz Joseph I. Der Kaiser und sein Reich. Eine politische Geschichte », Revue de I'IFHA [En ligne], Date de recension, mis en ligne le 01 janvier 2010, consulté le 22 septembre 2020. URL : http://journals.openedition.org/ifha/2241 ; DOI : https://doi.org/10.4000/ifha.2241

Ce document a été généré automatiquement le 22 septembre 2020.

(CIFHA 


\title{
Höbelt, Lothar, Franz Joseph I. Der Kaiser und sein Reich. Eine politische Geschichte
}

\author{
Paul Pasteur
}

1 En 150 pages, L.H., professeur à l'Université de Vienne et connu pour être l'un des rares historiens professionnels proche du FPÖ, propose une histoire politique de l'empereur François-Joseph et de son empire. De facto, il s'agit plutôt d'un essai qui désire revenir sur la manière de gouverner l'empire. Cela implique que cet ouvrage n'est guère conseillé aux étudiant-e-s débutant-e-s qui auront parfois du mal à appréhender certaines références à des faits ou événements non explicités. De plus, aucun appareil critique n'accompagne le texte, seules quelques références bibliographiques sont proposées en annexe où l'on trouve aussi la liste des chefs de gouvernement et des ministres des Affaires étrangères.

2 En dix chapitres, L.H. présente les presque soixante-dix années de règne de FrançoisJoseph, ce qui l'amène à ne consacrer qu'une ou deux pages à des épisodes aussi importants que celui des ordonnances linguistiques de Badeni. À propos de FrançoisJoseph qui, in fine, s'avère n'être guère au centre du livre, l'auteur revient sur sa formation et insiste, certainement à raison, sur le poids de son éducation militaire et sur la place que l'armée, le fait militaire, continueront à prendre dans sa vie. Pour L.H., c'est l'armée qui incarne ce que les Pays et Royaumes gérés par Vienne et le Royaume de Hongrie auraient en commun.

3 À propos des années de néo-absolutisme, l'auteur rappelle que le terme est fort mal choisi dans la mesure où c'est de facto la première fois dans l'empire habsbourgeois que le gouvernement pratique une politique absolutiste et que les diètes perdent absolument tout pouvoir. Cette période " néo-absolutiste » est décrite comme une dictature au service de la modernisation de l'empire. Dans tout l'ouvrage, on a l'impression que L.H. a tendance à sous-estimer les reformes menées par Marie-Thérèse et Joseph II et leurs conséquences. On pourrait aussi discuter la comparaison avec 
Napoléon III et la notion de « bonapartisme autrichien » désirant mettre en place une « démocratie paysanne ».

4 Contrairement à la tendance majoritaire dans l'historiographie autrichienne, L.H. s'intéresse de très près à la question nationale allemande. Il rappelle en effet l'impact de cette question nationale en 1848 pour les pays germanophones de l'empire. On relèvera néanmoins plusieurs anachronismes, l'utilisation du terme Mitteleuropa lors des débats entre Autrichiens de 1848 ou celle de Sudetendeutschen à la place de Deutschböhmen pour désigner les Allemands de Bohême et, en dépit (ou à cause) du ton provocateur de l'auteur, la persistance de nombreux clichés. La recherche de la formule nuit souvent au livre.

5 On appréciera un retour, même rapide, sur les réformes constitutionnelles du début des années 1860 , le diplôme d'octobre de 1860 et la patente de février 1861 et la réaction des Hongrois et le fait de revenir sur les Fundamentalartikel de 1871, éphémère tentative d'établir un sous-dualisme en Bohême, à l'exemple des Croates dans le Royaume de Hongrie.

6 À propos du début du vingtième siècle, L.H. souligne les divergences de vue entre Schönbrunn (l'empereur) et Belvédère (le prince héritier) et revient largement sur le caractère autoritaire des décisions prises lors de la Première Guerre mondiale.

7 L'objectif de l'essai est atteint : ouvrir la discussion.

8 Paul Pasteur (Université de Rouen) 